\title{
Pyridoxine Dependent Epilepsy: Is late onset a predictor for favorable outcome?
}

\author{
Authors \\ Rooy RLP de ${ }^{1}$ \\ Halbertsma FJ ${ }^{2}$ \\ Struijs $E A^{3}$ \\ Spronsen FJ van ${ }^{4}$ \\ Lunsing $\mathrm{RJ}^{5}$ \\ Schippers $\mathrm{HM}^{6}$ \\ Hasselt PM van ${ }^{7}$ \\ Plecko $\mathrm{B}^{8}$ \\ Wohlrab $\mathrm{G}^{8}$ \\ Whalen $\mathrm{S}^{9}$ \\ Benoist JF ${ }^{10}$ \\ Valence $S^{11}$ \\ Mills PB ${ }^{12}$ \\ Bok LA 2
}

Author affiliations

${ }^{1}$ Department of Pediatrics, Zuyderland Hospital, Heerlen, The Netherlands

${ }^{2}$ Department of Pediatrics, Màxima Medical Center, Veldhoven, The Netherlands

${ }^{3}$ Metabolic Unit, Department of Clinical Chemistry, VU University Medical Center, Amsterdam, The Netherlands

${ }^{4}$ Department of Metabolic Diseases, Beatrix Children's Hospital, University Medical Center Groningen,

University of Groningen, Groningen, The Netherlands

${ }^{5}$ Department of Child Neurology, University Medical Center Groningen, University of Groningen, Groningen, the Netherlands

${ }^{6}$ Department of Neurology, Sint Antonius Ziekenhuis, Nieuwegein and Utrecht, The Netherlands

${ }^{7}$ Department of Pediatric Metabolic Diseases, Wilhelmina Children's Hospital, University Medical Center (UMC) Utrecht, Utrecht, The Netherlands

${ }^{8}$ Division of Neurology, Children's Hospital, University of Zurich, Zurich, Switzerland

${ }^{9}$ UF de génétique clinique, APHP, Hôpital Armand Trousseau, Paris, France

${ }^{10}$ Centre de Référence des Maladies Héréditaires du Métabolisme, Service de Biochimie-Hormonologie, Hôpital Robert Debré, Paris, France

${ }^{11}$ Department of Child Neurology, APHP, Armand Trousseau Hospital, Paris, France

${ }^{12}$ Clinical and Molecular Genetics Unit, UCL Institute of Child Health, London, United Kingdom

Corresponding author

Dr Levinus A Bok, PO Box 7777, 5500MB Veldhoven, the Netherlands. E-mail: l.bok@mmc.nl 
Pyridoxine dependent epilepsy, late onset

\section{Abstract}

Aim: In pyridoxine dependent epilepsy (PDE), patients usually present with neonatal seizures. A small subgroup is characterized by late-onset beyond 2 months of age. We aim to analyze the observation of relatively good cognitive outcome in this subgroup of late-onset PDE patients

Methods: We retrospectively analyzed data from four metabolically and genetically confirmed late-onset patients with PDE due to antiquitin (ALDH7A1) deficiency. Data were analyzed regarding ALDH7A1 mutations, alpha-Aminoadipic semialdehyde ( $\alpha$-AASA) and pipecolic acid (PA) levels, medication during pregnancy, delivery, treatment delay, amount of seizures, pyridoxine dose, adjuvant therapy and findings on brain MRI.

Results: Results showed that three patients had relatively good outcome (IQ 80-97), while one patient did not undergo formal testing and was considered mildly delayed. We were unable to find a clear association between the above-mentioned variables and cognitive outcome, although a less severe genotype may be present in three patients, and maternal medication could be accountable for better outcome in two patients.

Interpretation: We suggest that favorable outcome in late onset PDE might be explained by a combination of factors. A yet unknown protective factor, different genetic variations, functional variation and secondarily variation in treatment regimens and absence of neonatal seizure induced brain damage.

\section{Abbreviated Title}

PDE: late onset associated with favorable outcome?

What this paper adds

- Late-onset PDE is a phenotype associated with relatively good outcome. 


\section{Introduction}

Most cases of pyridoxine dependent epilepsy (PDE) are due to mutations in the gene, located on $5 q 31^{1,2}$, which encodes for antiquitin, the $\alpha$-AASA dehydrogenase enzyme within the lysine degradation pathway. Antiquitin deficiency results in alpha-aminoadipic semialdehyde ( $\alpha$-AASA) and pipecolic acid (PA) accumulation in blood plasma, urine and cerebrospinal fluid. Most patients present with intractable seizures in the neonatal period. Rarely PDE patients present after the neonatal period. In the Netherlands, the incidence is 1 in 276.000 newborns ${ }^{3,4}$. The incidence of late-onset PDE is an estimated $10 \%$ of PDE, so roughly 1 in 2.500 .000 .

In 2001, Baxter reported a more favorable outcome in late onset PDE. However, PDE could, at that time, not be confirmed by metabolic and/or DNA testing and thus not differentiated from pyridoxine responsive seizures for example ${ }^{5}$. Hence it is unclear whether these patients were indeed suffering from antiquitin deficiency, or from a different form of pyridoxine dependent epilepsy.

Diagnosis can be blurred by non-neuronal systemic symptoms or ambiguous pyridoxine response. Currently, measurement of alpha-aminoadipic semialdehyde in urine supports the diagnosis, followed by molecular investigations of the Antiquitin-gene ${ }^{2,3}$.

Treatment of PDE is primarily based on a daily pyridoxine dose of $10-30 \mathrm{mg} / \mathrm{kg} /$ day for infants, while for neonatal patients a daily maximum of $200 \mathrm{mg}$ is recommended ${ }^{5,6}$. Adjuvant treatment options include dietary lysine restriction and arginine supplementation ${ }^{7,8}$.

Without adequate treatment, PDE is a potentially lethal condition. Despite being seizure free, $75 \%$ of the patients treated with pyridoxine are mentally low average or even retarded $(I Q<85 \text { or } 50 \% 1 Q<70)^{7,12}$. Prognosis in PDE is probably influenced by several different factors and cannot be predicted easily. One of these prognostic factors might be the patient age at seizure onset, which has been reported previously ${ }^{5}$.

\section{Methods}

We retrospectively collected data from specific patients with a metabolically (increased $\alpha$-AASA in urine) as well as genetically confirmed PDE with a late onset, identified in the PDE network database. The PDE network database is a non-formal database, based on intercollegial communication between metabolic PDE centers, including the Dutch centers. Late onset was defined as onset of seizures beyond 1 month of age.

Data were obtained, if applicable from patients' physicians through a questionnaire concerning outcome and possible predicting cofactors (pregnancy and labor complications, onset of seizures, metabolic and genetic testing, treatment, outcome and MRI as well as EEG findings).

Outcome was measured as IQ or development by age appropriate assessment. Bayley Scale of Infant and Toddler Development -Dutch adaptation (Bayley-II-NL) or Snijders-Oomen Non-verbal intelligence test (revised) (SON-R 81), a standardized Dutch intelligence test and the age appropriate assessment by 'van Wiechenschema' (vWS), which is based on development of healthy full-term-born children ${ }^{10-12}$.

Data were compared with those in early onset PDE patients as reported in the literature.

\section{Results}

In the PDE network database, four patients were identified that met the inclusion criteria.

The main outcome IQ was available in three patients $(81,95$, and 97$)$ and appeared higher than expected based on average IQ in early onset PDE patients (IQ $72 \pm$ SD 19) $)^{12}$.

One patient did not undergo validated developmental testing, but was considered having mild-moderate delay from a clinical perspective, as well as from attending normal school with extra support ${ }^{12}$. Major behavioral disturbances or autistic spectrum disorders were not observed in any patient. All patients were seizure free.

Results are shown in table 1.

MRI was normal in three of our four patients. However, patient 1 showed a hypoplastic isthmus of the corpus callosum and moderately widened cerebrospinal fluid spaces. 


\section{Discussion}

The main observation is that our study confirms that cognitive development may be better in late onset PDE, as three out of four PDE patients had IQ levels within the normal range while in typical early onset PDE, 75\% of children are mentally delayed ${ }^{12}$. Follow-up tests to further evaluate cognitive development over time in our patients are not yet available.

The role of various factors which might explain good outcome in late onset PDE are discussed below.

A genotype phenotype relation was previously assumed, but has not been established in PDE ${ }^{2,13}$. Interestingly, three patients presented here had uncommon mutations with unknown residual enzyme activity. Although speculative, residual enzyme activity might be preserved, which could explain late onset and better prognosis. Patient 1, however, was homozygous for the common Dutch mutation c.1279G>C (formerly designated as c.1195G $>$ C) reported as having an unfavorable outcome ${ }^{12}$.

Comparing PA levels at time of diagnosis of early onset patients to the ones observed here, two patients ( 2 and 3 ) had low to medium PA values ${ }^{3}$. Patients 1 and 4 showed a relatively high value of plasma PA, which could be a reflection of higher lysine intake or low residual enzyme activity. However, these patient's outcome in terms of intelligence were not worse compared to others in this study.

In early onset PDE, $\alpha$-AASA values range from 4.0 to $29 \mathrm{mmol} / \mathrm{mol}$ creatinine in urine at the time of diagnosis ${ }^{3}$. Again, in two patients, the $\alpha$-AASA levels in urine were moderately elevated. One patient (patient 1 ) showed a strongly increased urinary $\alpha$-AASA level of $101 \mathrm{mmol} / \mathrm{mol}$ creatinine at diagnosis, but nevertheless the patient had a normal cognitive outcome. In patient 4, urinary $\alpha$-AASA concentration was not available.

Delay in treatment was regarded as the time between seizure onset and start of pyridoxine treatment and ranged from none to nine months. Delay in treatment in this cohort showed notable differences (table 1) that could not be related to the favorable outcome in our patients. This is in disagreement with the findings of a UK national survey that showed treatment delays varying from 1 day to 53 weeks in early onset PDE, associating longer delay with disadvantageous prognosis ${ }^{5}$.

The received pyridoxine dose of patients in this study, as shown in Table 1, was varying from 6 to 22 $\mathrm{mg} / \mathrm{kg} / \mathrm{day}$, based on an age-dependent estimated weight, either in a single daily dose or in two uneven daily doses (e.g. 200mg in the morning and $100 \mathrm{mg}$ in the evening). Currently, the recommended dose of pyridoxine is $15-30 \mathrm{mg} / \mathrm{kg} /$ day in early infancy, reducing to doses ranging from 0.5 to $2.0 \mathrm{mg} / \mathrm{kg} /$ day in later life ${ }^{5}$. This recommended dose was based on early-onset patients however. The patients we studied were treated with pyridoxine dosages within this recommended range. Higher doses might be associated with better behavioral and electroencephalographical outcome ${ }^{5}$. This however does not count for the patients included in this study, as they received relatively low doses.

Three of the patients in our study received monotherapy with pyridoxine, whereas adjuvant treatment with lysine restriction and arginine supplementation have been suggested ${ }^{6,7}$. Patient 1 started lysine restriction at the age of 2.5 years, whilst IQ-testing was performed at 2 years of age. Based on these data we cannot conclude that there might be a positive effect of lysine restriction on IQ.

There were differences with respect to medication during pregnancy. The mother of patient 2 used mercaptopurin and vitamine B6, as a therapy for Crohn's disease. Vitamin B6 was used in the advised daily dose of $2 \mathrm{mg}$. Although mercaptopurin occasionally has been associated with congenital defects in the newborn and pregnancy complications ${ }^{14}$, the current opinion in the Netherlands is that a low dose of mercaptopurin can safely be used during pregnancy ${ }^{15}$. Possible benefits from mercaptopurin use during pregnancy could not be found in literature. A neuroprotective effect seems very unlikely. Thus, for our patient, we could not find a clear answer on possible disadvantages or benefits resulting from maternal mercaptopurin use during pregnancy, concluding that it is highly unlikely to be of any influence on our patients' good outcome.

The use of folic acid and vitamin B12 in the mother of patient 1 and 3 respectively is noteworthy. No studies investigating the effects of maternal folic acid nor vitamin B12 use during pregnancy on epilepsy syndromes in infants were found, nor a relation with these epilepsy syndromes. Positive effects of folinic acid in PDE however, have been described before ${ }^{16}$. Positive effects of vitamin B12 use in PDE have not yet been described. Vitamin B12 and folic acid metabolism are linked in the remethylation cycle of homocysteine, but it's role in PDE is not determined.

The mother of patient 4 received glucocorticoids because of possible preterm birth at 26 weeks. A relation 
between maternal glucocorticoid use and seizures in their child was not found in literature, and therefore cannot be held responsible for favorable outcome in late onset PDE.

Seizure control has recently been suggested as a factor in neurocognitive development. It is assumed that neonatal seizures regardless of their etiology are a great threat for neurocognitive development, especially if they occur in the first weeks of life ${ }^{17}$. This might be applicable in this study of late-onset PDE patients. Therefore, patients with late onset of seizures and good outcome are of significant importance in unraveling the pathophysiology of PDE, which also might enhance the prognosis of all PDE patients.

The observations in this study leave room for speculations. One might speculate that there is a yet to be discovered protective biochemical -detoxification- process responsible for good outcome in late-onset PDE patients.

\section{Study Limitations}

In PDE, and many other inborn-errors of metabolism, low number of patients impedes research. This certainly applies for the subgroup of late-onset PDE patients. Nevertheless, only by sharing observations, understanding of PDE can progress.

Follow-up data concerning developmental outcome were incomplete for patient 4. For this patient, only clinical observations were available, as no validated developmental test was performed. This patient is considered to be mildy delayed, given the fact he attends a normal school with extra support. From this perspective, we still think it is off added value to compare this definite late onset patient to others in this study, especially since lateonset PDE is such a rare disease.

\section{Conclusion}

In late onset PDE, IQ tends to be higher than in the majority of classic early onset PDE. There is a possible role in relation to outcome for genetics, as a possible favorable genotype-phenotype correlation, metabolic factors as lower AASA and lower pipecolic acid levels, adjuvant therapy as lysine restriction or maternal medication during pregnancy as folic acid. In comparison with reported cases no uniform explanation for mild outcome in these studied late-onset PDE patients could be found; except the coincidence of (prolonged) absence of neonatal seizures. There might be a yet to be discovered protective factor in the patients.

\section{References}

1. Bok LA, Struys E, Jakobs C, Been JV, Willemsen MAAP. Pyridoxine Afhankelijke Epilepsie. Ned Tijdschr Neurol en Neuroch 2007; 108: 51-56.

2. Mills PB, Struys E, Jakobs $C$, Plecko B, Baxter $P$, Baumgartner $M$ et al. Mutations in antiquitin in individuals with pyridoxine-dependent seizures. Nat Med 2006; 12: 307-309

3. Bok L, Struys E, Willemsen M, Been J; Pyridoxine-dependent seizures in Dutch patients: diagnosis by elevated urinary alpha-aminoadipic semialdehyde levels; Arch DisChild 2007; 92:687-689

4. van Karnebeek, C.D., Tiebout, S.A., Niermeijer, J., Poll-The, B.T., Ghani, A., Coughlin C.R. $2^{\text {nd }}$, van Hove, J.L., Richter, J.W., Christen, H.J., Gallagher, R., Hartmann, H., Stockler-Ipsiroglu, S.; Pyridoxine-Dependent Epilepsy: An Expanding Clinical Spectrum. Pediatr Neurol. 2016 Jun;59:6-12

5. Baxter P; 2001; Pyridoxine Dependent/Responsive Seizures; in Vitamin Responsive Conditions in Paediatric Neurology (pp109-165); London, Mac Keith Press

6. Stockler S, Plecko B, Gospe Jr SM et al.; Pyridoxine dependent epilepsy and antiquitin deficiency clinical and molecular characteristics and recommendations for diagnosis, treatment and follow-up, Mol. Genet. Metab. 104 (2011) 48-60

7. Van Karnebeek CD, Hartmann H, Jaggumantri S, Bok LA, Cheng B, Connolly M, Coughlin CR 2nd, Das AM, Gospe SM Jr, Jakobs C, van der Lee JH, Mercimek-Mahmutoglu S, Meyer U, Struys E, Sinclair G, Van Hove J, Collet JP, Plecko BR, Stockler S; Lysine restricted diet for pyridoxine-dependent epilepsy: first evidence and future trials; Mol Genet Metab. 2012 Nov;107(3):335-44

8. Van Karnebeek CD, Jaggumantri S; Current Treatment and management in Pyridoxine-Dependent Epilepsy; Curr Treat Options Neurol. 2015 Feb;17(2):335.

9. Van der Meulen BF, Ruiter SAJ, Lutje Spelberg HC, Smrkovsky M. Bayley Scales of Infant Development II Nederlandse Versie. Handleiding. Amsterdam: Harcourt Publishers, 2005 
10. Tellegen, P.J. \& Laros, J.A; SON-R 6-40. Snijders-Oomen niet-verbale intelligentietest. I. Verantwoording. Amsterdam: Hogrefe uitgevers; 2011

11. Laurent de Angulo MS, Brouwers-de Jong EA, Bijlsma-Schlösser JFM (eds), et al. Ontwikkelingsonderzoek in de jeugdgezondheidszorg: het Van Wiechenonderzoek - De Baecke-Fassaert Motoriektest. 4 e dr. Assen: Van Gorcum; 2008

12. Bok LA, Halbertsma FJ, Houterman S, Wevers RA, Vreeswijk C, Jakobs C, Struys E, van der Hoeven JH, Sival DA, Willemsen MA. Long-term outcome in pyridoxine-dependent epilepsy. Developmental Medicine \& Child Neurology 2012; 54: 849-854.

13. Scharer, G., Brocker, C., Vasiliou, V., Creadon-Swindell, G., Gallagher, RC., Spector, E., Van Hove, JL.; The genotypic and phenotypic spectrum of pyridoxine-dependent epilepsy due to mutations in ALDH7A1. J Inherit Metab Dis. 2010 Oct;33(5):571-81.

14. Nørgård B, Pedersen L, Christensen LA, Sørensen HT; Therapeutic drug use in women with Crohn's disease and birth outcomes: a Danish nationwide cohort study; Am J Gastroenterol. 2007;102(7):1406.

15. Francella A, Dyan A, Bodian C, Rubin P, Chapman M, Present DH; The safety of 6-mercaptopurine for childbearing patients with inflammatory bowel disease: a retrospective cohort study; Gastroenterology. 2003;124(1):9.

16. Gallagher R.C., Van Hove J.L., Scharer G., Hyland K., Plecko B., Waters P.J., Mercimek-Mahmutoglu S., Stockler-Ipsiroglu S., Salomons G.S., Rosenberg E.H., Struys E.A., Jakobs C.; Folinic acid-responsive seizures are identical to pyridoxine-dependent epilepsy. Ann Neurol. 2009 May;65(5):550-6

17. Chapman, K. E., Specchio, N., Shinnar, S. and Holmes, G. L. , Seizing control of epileptic activity can improve outcome. Epilepsia 2015; 56:1482-1485.

\begin{tabular}{|c|c|c|c|c|}
\hline & Patient 1 & Patient 2 & Patient 3 & Patient 4 \\
\hline Sex & Male & Female & Female & Male \\
\hline $\begin{array}{l}\text { Medication during } \\
\text { pregnancy }\end{array}$ & None & Mercaptopurine $75 \mathrm{mg}$ & None & None \\
\hline Abnormal fetal movements & None & Hiccups & None & None \\
\hline Vitamins during pregnancy & $\begin{array}{l}\text { Vitamin B12 IM } \\
1000 \mu \mathrm{g} \text { monthly }\end{array}$ & Vitamin B6 2mg (=ADD*) & Folic Acid & None \\
\hline Pregnancy complications & $\begin{array}{l}\text { Multiple pregnancy } \\
\text { (Twins) }\end{array}$ & Maternal Crohn's Disease & Placental problems & $\begin{array}{l}\text { Glucocoticoid for preterm } \\
\text { labour at } 26 \text { weeks of gestation }\end{array}$ \\
\hline Labor complications & None & Meconium staining & None & Preterm, 31 gestational weeks \\
\hline Apgar & $9 / 10$ & $7 / 9$ & $-/-$ & $8 / 10$ \\
\hline Neonatal period & Normal & Normal & Normal & $\begin{array}{l}\text { Transient neonatal respiratory } \\
\text { distress } \\
\text { Transient enteropathy }\end{array}$ \\
\hline First seizures & $10^{\text {th }}$ week & $20^{\text {th }}$ week & $9^{\text {th }}$ week & 3 months \\
\hline First pyridoxine & $13^{\text {th }}$ week & $14^{\text {th }}$ month & $12^{\text {th }}$ week & 3 months \\
\hline $\begin{array}{l}\alpha \text {-AASA in urine at } \\
\text { diagnosis ( } \mathrm{mmol} / \mathrm{mol} \\
\text { creatinin) }\end{array}$ & 101 & 9.9 & 13 & Not available \\
\hline Mutation* & $\begin{array}{l}\text { c. } 1279 \mathrm{G}>\mathrm{C} \\
\text { c. } 1279 \mathrm{G}>\mathrm{C}\end{array}$ & $\begin{array}{l}\text { c. } 346 C>T \\
\text { c. } 1432 T>A\end{array}$ & $\begin{array}{l}\text { c. } 512 C>T \\
\text { c. } 512 C>T\end{array}$ & $\begin{array}{l}\text { c. } 1364 T>C \\
\text { c. } 1364 T>C\end{array}$ \\
\hline Amino acid change* & $\begin{array}{l}\text { p.Glu427GIn } \\
\text { p.Glu427GIn }\end{array}$ & $\begin{array}{l}\text { p.GIn116Stop } \\
\text { p.Cys478Ser }\end{array}$ & $\begin{array}{l}\text { p.Ala199Val } \\
\text { p.Ala199Val }\end{array}$ & $\begin{array}{l}\text { p.Leu455Pro } \\
\text { p.Leu455Pro }\end{array}$ \\
\hline $\begin{array}{l}\text { Pipecolic acid in plasma } \\
(\mu \mathrm{mol} / \mathrm{l})\end{array}$ & 10.9 & 3.0 & 4.91 & 16.4 \\
\hline Outcome: current age & 4years & 4 years & 10 years & 4 years \\
\hline Pyridoxine dose & $100 \mathrm{mg}$ & $\begin{array}{l}300 \mathrm{mg} \text { ( } 200 \text { morning/100 } \\
\text { evening) }\end{array}$ & $300 \mathrm{mg}$ & $250 \mathrm{mg}$ \\
\hline Current antiepileptic drugs & None & None & None & n.a. ${ }^{*}$ \\
\hline Lysine restricted diet & $\begin{array}{l}\text { Yes, starting at } 2,5 \\
\text { years }\end{array}$ & No & No & No \\
\hline $\mathrm{IQ} / \mathrm{MD}$ & Bailey 97 (age 2) & Bailey 95 (age 2) & SON-R 81; concentration deficits & $\begin{array}{l}\text { Attends normal school with } \\
\text { extra support }\end{array}$ \\
\hline Behavior & Normal & Normal & Normal & Shy \\
\hline MRI: at diagnosis & $\begin{array}{l}\text { Hypoplastic isthmus } \\
\text { Moderately widened } \\
\text { CSF* spaces }\end{array}$ & Normal & Normal & Normal \\
\hline EEG at diagnosis & $\begin{array}{l}\text { Spike waves } \\
\text { centroparietal }\end{array}$ & $\begin{array}{l}\text { Normal background, no } \\
\text { epileptic discharges }\end{array}$ & $\begin{array}{l}\text { Seizure pattern } 01 / \mathrm{O}^{*}, \\
\text { independent. Normal } \\
\text { background activity }\end{array}$ & $\begin{array}{l}\text { Spikewaves right temporo- } \\
\text { parietal }\end{array}$ \\
\hline
\end{tabular}




\begin{tabular}{|l|l|l|l|l|}
\hline EEG at follow-up & Normal Normal & Normal & Normal \\
\hline
\end{tabular}

\section{Table 1. Patient specific clinical characteristics}

$A D D=$ advised daily dose;

$\mathrm{CSF}=$ cerebrospinal fluid;

n.a. $=$ not available

$\mathrm{O}=$ occipital electrode;

$\mathrm{IQ}=$ intelligence quotient;

$\mathrm{MD}=$ mental development

SON-R=Snijders-Oomen Non-verbal intelligence test (revised)

Reference range for urinary $\alpha$-AASA: $<1 \mathrm{mmol} / \mathrm{mol}$ creatinin

Reference range for plasma Pipecolic Acid: 3.75-10.8 umol/L (in first week of life); 0.7-2.46 umol/L (after first week)

*The reference sequence used for reporting DNA variants is NM_001182.4 